\title{
THE FORMATION OF SRZ ON A FOURTH GENERATION SINGLE CRYSTAL SUPERALLOY APPLIED WITH ALUMINIDE COATING
}

\author{
Y. Matsuoka, Y. Aoki, K. Matsumoto, A. Satou, T. Suzuki, K. Chikugo, and K. Murakami \\ Ishikawajima-harima Heavy Industries Co., Ltd. Japan
}

Keywords: $4^{\text {th }}$ generation Ni-base SC superalloy, Aluminide coating, SRZ reduction

\begin{abstract}
The formation behavior of Secondary Reaction Zone (SRZ) for a $4^{\text {th }}$ generation nickel-base single crystal (SC) superalloy with aluminide coating was investigated. The growth of SRZ is supposed to be dominantly controlled by the inward diffusion of aluminum from the coating layer to the substrate. The outward diffusion of $\mathrm{Ru}$ from the substrate to the coating layer may also contribute to SRZ formation. A remarkable reduction of SRZ was accomplished by depositing thin films composed of Co and/or $\mathrm{Ru}$ on the alloy surface prior to aluminide coating, that is expected to restrict the diffusion of $\mathrm{Al}$ and $\mathrm{Ru}$ between the coating layer and the substrate.
\end{abstract}

\section{Introduction}

The $3^{\text {rd }}$ generation Ni-base SC superalloys, containing high concentrations of rhenium, are used in jet engine turbine blades for their outstanding high-temperature mechanical strength. However, applying aluminide coating to these alloys, necessary to improve oxidation resistance, causes a harmful intermediate layer under the coating. This intermediate layer called SRZ, is believed to degrade mechanical properties of the alloys [1]. SRZ consists of Topologically Close Packed (TCP) phase, which contains the refractory elements such as $\mathrm{Re}$ or $\mathrm{W}$, and needle-like gamma phase in a matrix of gamma prime [1]. Since SRZ formation does not occur in alloys with lower Re concentrations, the higher levels of Re may be important in SRZ formation. It is suggested that SRZ is derived from the local compositional changes due to diffusion of $\mathrm{Al}$ and other elements between the coating layer and the substrate [2]. The effect of stress is also suggested [1].

Recently the $4^{\text {th }}$ generation SC superalloys[4] have achieved further thermal stability and remarkable creep strength by the addition of $\mathrm{Ru}$, which is expected to restrict the formation of TCP [3]. Since these alloys also contain high concentrations of $\mathrm{Re}$, as is the case of the $3^{\text {rd }}$ generation SC superalloys, SRZ caused by aluminide coating may become a significant issue. We confirm that the application of aluminide coating degrades the creep-rupture strength of the $4^{\text {th }}$ generation SC superalloy accompanied with the formation of SRZ. It is supposed that SRZ contributes considerably to this mechanical degradation.

This study investigated the formation behavior of SRZ caused by aluminide coating for a $4^{\text {th }}$ generation SC superalloy. Moreover, some additional coatings to reduce SRZ by restricting the diffusion of elements between the coating layer and the substrate will be suggested.

\section{Formation Behavior of SRZ Caused by Aluminide Coating}

With the aim of clarifying the mechanism of SRZ growth, the formation behavior of SRZ and the diffusion behavior of the elements under several oxidation conditions were examined.

\section{$\underline{\text { Experimental Procedures }}$}

A $4^{\text {th }}$ generation Ni-base SC superalloy, TMS-138, was used as the substrate material, as shown in Table I. Aluminide coating was applied by conventional pack-cementation method.

Table I. Chemical Composition in wt.\% of Alloy TMS-138

\begin{tabular}{|l|l|l|l|l|l|l|l|l|l|}
\hline $\mathrm{Ni}$ & $\mathrm{Cr}$ & $\mathrm{Co}$ & $\mathrm{Mo}$ & $\mathrm{W}$ & $\mathrm{Al}$ & $\mathrm{Ta}$ & $\mathrm{Re}$ & $\mathrm{Ru}$ & $\mathrm{Hf}$ \\
\hline Bal. & 2.9 & 5.9 & 2.9 & 5.9 & 5.9 & 5.6 & 4.9 & 2.0 & 0.10 \\
\hline
\end{tabular}

A static oxidation test in air at $1273 \mathrm{~K}$ for 2000 hours was carried out for the specimen with aluminide coating to examine the time dependence of SRZ growth. Static oxidation tests in air at a variety of temperatures from $1173 \mathrm{~K}$ to $1373 \mathrm{~K}$ in 500 hours were also carried out to examine the temperature dependence. The geometry of the specimen was $20 \mathrm{~mm}$ in diameter and $3 \mathrm{~mm}$ in thickness. The cross-sectional microstructures were analyzed by optical microscopy and scanning electron microscopy (SEM). The X-ray intensities of the elements were measured by electron probe micro analyzer (EPMA). The diffusion behavior of an element was evaluated by the ratio of X-ray intensity to the substrate.

\section{$\underline{\text { Results }}$}

Microstructures. The cross-sectional microstructure of the specimen with aluminide coating after the oxidation test at $1373 \mathrm{~K}$ in 500 hours is shown in Figure 1. The gamma matrix has disappeared under the diffusion zone of coating, where large amount of precipitates composed of refractory elements such as $\mathrm{Re}, \mathrm{W}$, or Mo were formed. (This region is defined as SRZ in this paper.) Granular precipitates distributed in the upper part of SRZ, and needle-like precipitates perpendicular to the interface distributed below. SRZ expanded toward the substrate as the oxidation time became longer or the temperature became higher.

Al was distributed from the coating layer to the SRZ after the oxidation test at $1173-1273 \mathrm{~K}$. This indicates that $\mathrm{Al}$ had diffused inward from the coating layer to the substrate during the oxidation test. The X-ray intensity of $\mathrm{Al}$ just under the coating layer had increased to about 1.8 times as high as that in the substrate after 1000 hours at $1273 \mathrm{~K}$. After the highest temperature oxidation test at $1373 \mathrm{~K}, \mathrm{Al}$ scarcely remained in the coating layer. Its X-ray intensity in the coating layer had decreased to as low as about $60 \%$ of that in the substrate. On the other hand, Ru was concentrated in the coating layer while it was depleted under the coating layer after the oxidation tests. This indicates that $\mathrm{Ru}$ had diffused outward from the substrate to the coating layer. The X-ray 
intensity of Ru in the coating layer had increased to about twice as high as that in the substrate after 1000 hours at $1273 \mathrm{~K}$. While that under the coating layer had decreased to as low as about $20 \%$ of that in the substrate.
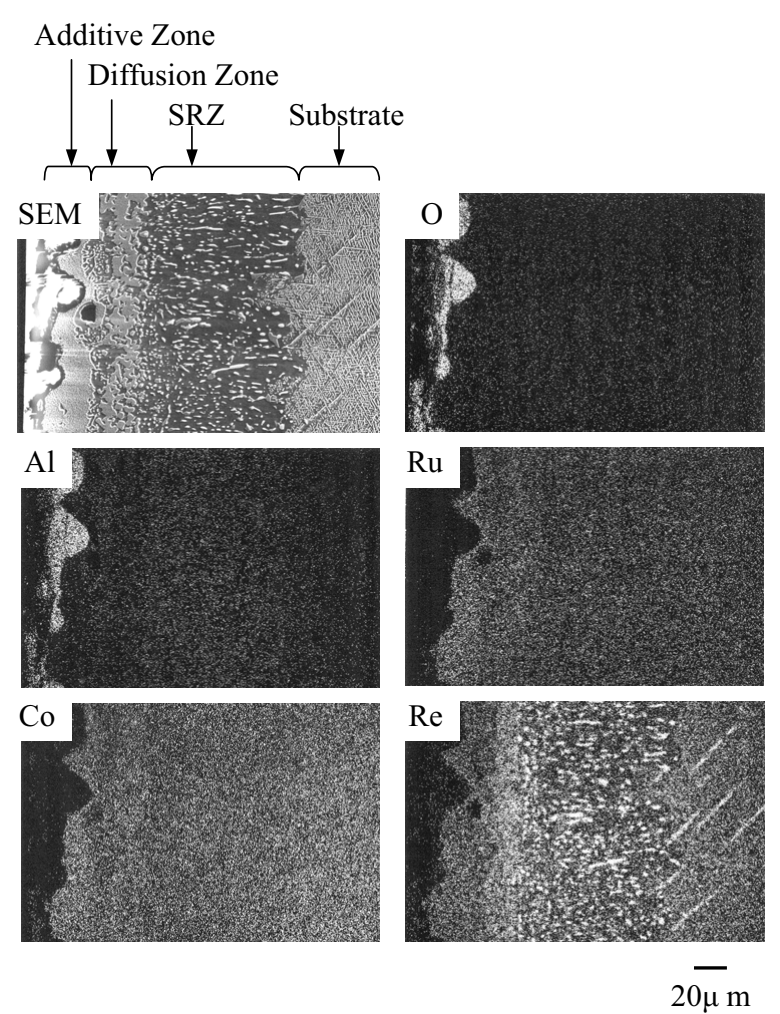

Figure 1. Cross-sectional microstructure and characteristic $\mathrm{X}$-ray images of the specimen with aluminide coating after the oxidation test in air at $1373 \mathrm{~K}$ in 500 hours.

SRZ Thickness. The layer thickness of SRZ, $d$, was defined as the average thickness from just under the diffusion zone to the bottom of the SRZ, was measured as shown in Figure 2. The dependence of SRZ thickness $d$ on the oxidation time at $1273 \mathrm{~K}$ and the oxidation temperature in 500 hours were examined.

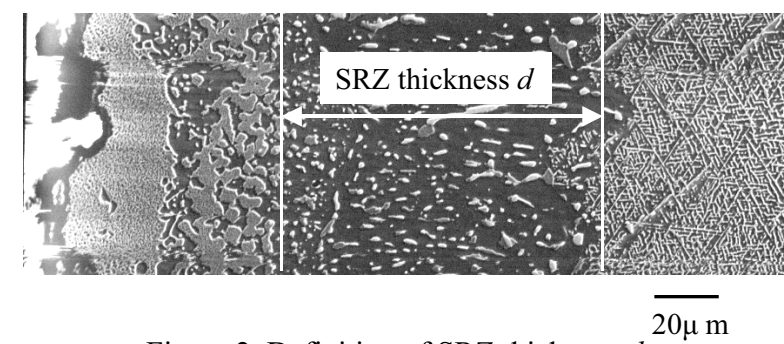

Figure 2. Definition of SRZ thickness $d$

Time dependence: The time dependence of SRZ thickness $d$ at $1273 \mathrm{~K}$ is shown in Figure 3. It is confirmed that $d$ increases in proportion to the square root of time $\sqrt{ } t$.

Temperature dependence: The temperature dependence of SRZ thickness $d$ in 500hours is shown in Figure 4. The linear relationship is observed between $\ln (d)$ and $1 / T$ in the temperature ranged from $1173 \mathrm{~K}$ to $1323 \mathrm{~K}$. The growth rate of thickness $d$ tends to decrease at higher temperature than $1323 \mathrm{~K}$.

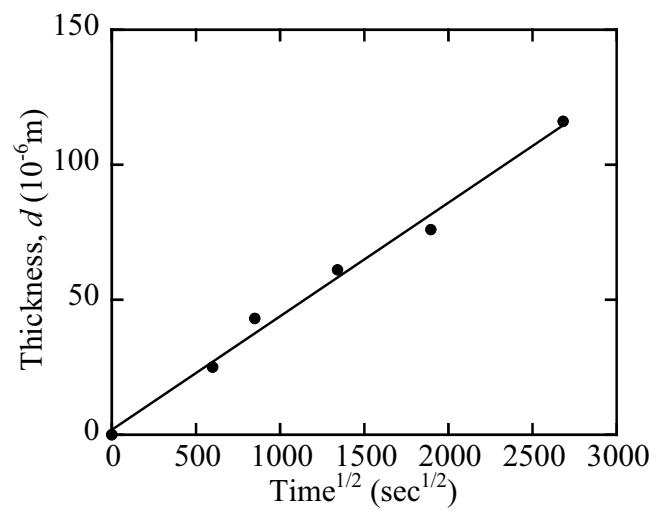

Figure 3. Time dependence of SRZ thickness $d$ of the specimen with aluminide coating at $1273 \mathrm{~K}$.

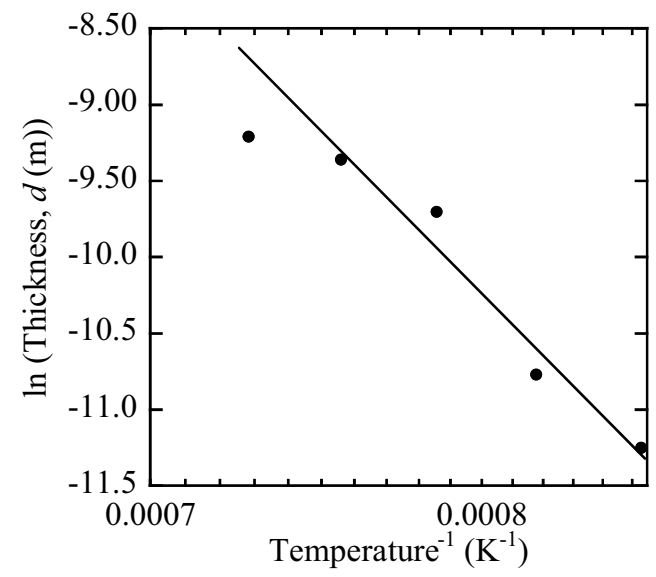

Figure 4. Temperature dependence of SRZ thickness $d$ of the specimen with aluminide coating in 500hours.

\section{$\underline{\text { Discussion }}$}

The growth kinetics of SRZ will be discussed here on the assumption that the oxidation test can be regarded as purely thermal exposure. Namely the effects of oxidation reactions or inward diffusion of oxygen are not included in following discussions.

The results of EPMA analysis shows that Al diffuses inward from the coating layer to the substrate and $\mathrm{Ru}$ diffuses outward from the substrate to the coating layer during high temperature exposure. The increase of $\mathrm{Al}$ content in the substrate due to its inward diffusion from the coating layer may cause phase transformation from gamma into gamma prime, leading to the formation of SRZ. Also, the decrease of gamma phase may oblige the refractory elements such as Re or W in it to be supersaturated and separate into TCP. So it can be said that the growth of SRZ is predominantly controlled by the inward diffusion of $\mathrm{Al}$ from the coating layer and the presence of refractory elements in the substrate. On the other hand, the decrease of Ru content in the 
substrate due to its outward diffusion into the coating layer may cause local phase instability [3, 4]. It may also promote the formation of SRZ.

SRZ thickness $d$ increases in proportion to the square root of time $\sqrt{ } t$ until 2000 hours at $1273 \mathrm{~K}$, as shown in Figure 3. This indicates that the growth of SRZ is dominantly controlled by the diffusion process. The linear relationship is also observed between $\ln (d)$ and $1 / T$ in the temperature ranged from $1173 \mathrm{~K}$ to $1273 \mathrm{~K}$, as shown in Figure 4. This indicates that the growth of SRZ is subject to the thermal activation process. At higher temperatures than $1323 \mathrm{~K}$, the growth rate of SRZ tends to decrease. $\mathrm{Al}$ in the coating layer is consumed to form oxide scale and also diffuses into the substrate. This results in the depletion of $\mathrm{Al}$ in the coating layer. Both the oxidation reaction rate and the diffusion rate increase as the temperature becomes higher, accelerating the $\mathrm{Al}$ depletion rate. Therefore $\mathrm{Al}$ is exhausted in a shorter time at higher temperature. Since the chemical potential of an element is related to its concentration, this $\mathrm{Al}$ depletion in the coating layer reduces the driving force for diffusion. This may be the main reason for the reduction of the growth rate of SRZ.

Generally, when the growth of an internal reaction layer is controlled by the diffusion process of element $i$, the thickness of that layer, $d_{\mathrm{i}}$, can be described by the following equation (1) as a function of the diffusion coefficient $D_{\mathrm{i}}\left(\mathrm{m}^{2} \mathrm{sec}^{-1}\right)$ and the diffusion time $t(\mathrm{sec})[5]$ :

$$
d_{\mathrm{i}} \propto \sqrt{ } D_{\mathrm{i}} \sqrt{ } t
$$

$D_{\mathrm{i}}$ can be described by the following equation (2) as a function of absolute temperature $T(\mathrm{~K})[6]$ :

$$
D_{\mathrm{i}}=D_{0} \exp \left(Q_{\mathrm{i}} / \mathrm{R} T\right)
$$

Where $D_{0}$ is the frequency factor $\left(\mathrm{m}^{2} \mathrm{sec}^{-1}\right), Q_{\mathrm{i}}$ is the activation energy of diffusion of element $\mathrm{i}\left(\mathrm{J} \mathrm{mol}^{-1}\right)$, and $\mathrm{R}$ is the gas constant $\left(\mathrm{J} \mathrm{K}^{-1} \mathrm{~mol}^{-1}\right)$.

When temperature is constant, $D_{\mathrm{i}}$ is constant from the equation (2). Then $d_{\mathrm{i}}$ is proportional to $\sqrt{t}$ from the equation (1).

When time is constant, the equations (1) and (2) arrived at the following equation (3):

$$
\ln \left(d_{\mathrm{i}}\right)=-Q_{\mathrm{i}} / 2 \mathrm{R} T+\text { Const. }
$$

The equation (3) shows the linear relationship between $\ln \left(d_{i}\right)$ and $1 / T$. The gradient of $\ln \left(d_{\mathrm{i}}\right)-1 / T$ line equals to the value of $-Q_{\mathrm{i}} / 2 \mathrm{R}$.

The experimental result shows $d \propto \sqrt{ }$ at $1273 \mathrm{~K}$. The diffusion coefficient calculated from the gradient of regression line of the $d-\sqrt{ } t$ plot in figure 3 is $1.87 \times 10^{-15}\left(\mathrm{~m}^{2} \mathrm{sec}^{-1}\right)$. This is very similar to the diffusion coefficient of $\mathrm{Al}$ in gamma prime, $6.03 \times 10^{-15}\left(\mathrm{~m}^{2}\right.$ $\mathrm{sec}^{-1}$ ) at $1187-1513 \mathrm{~K}$, calculated from the reported value of the activation energy [7]. The experimental result also shows the linear relationship between $\ln (d)$ and $1 / T$. The gradient of the regression line of the $\ln (d)-1 / T$ plot through the points from $1223 \mathrm{~K}$ to $1323 \mathrm{~K}$ in Figure 4 is about $-2.1 \times 10^{4}$. The value of $Q_{\mathrm{i}}$ calculated from this is about $3.5 \times 10^{5}\left(\mathrm{~J} \mathrm{~mol}^{-1}\right)$. This is also similar to the reported value of the activation energy of diffusion of $\mathrm{Al}$ in $\mathrm{Ni}, Q_{\mathrm{Al}}=2.7 \times 10^{5}\left(\mathrm{~J} \mathrm{~mol}^{-1}\right)$ at $1372-1553 \mathrm{~K}$ [8], and in gamma prime, $Q_{\mathrm{Al}}=1.6 \times 10^{5}\left(\mathrm{~J} \mathrm{~mol}^{-1}\right)$ at $1187-1513 \mathrm{~K}$ [7]. The quantitative evaluation of the influence of Ru diffusion is difficult because of the lack of data.

From the above results and discussions, it can be said that the growth of SRZ is predominantly controlled by the diffusion of $\mathrm{Al}$ from the coating layer to the substrate and by the outward diffusion of $\mathrm{Ru}$ from the substrate to the coating layer.

\section{SRZ Reduction by Additional Coating}

Since SRZ is supposed to be caused by the diffusion of $\mathrm{Al}$ and $\mathrm{Ru}$ between the coating layer and the substrate, it is expected that the existence of an internal layer at the coating/substrate interface preventing the diffusion of these elements can reduce SRZ. Thus, an additional coating was applied prior to aluminide coating in an attempt to form the internal layer.

\section{$\underline{\text { Experimental Procedures }}$}

A thin film composed of $\mathrm{Co}$ and/or $\mathrm{Ru}$ was deposited on the specimen surface by sputtering, as an additional coating. The composition and thickness of the deposited films are shown in Table II. Then aluminide coating was applied following a heat treatment. Static oxidation tests were carried out in air at $1373 \mathrm{~K}$ in 500 hours for these specimens. The cross-sectional microstructures before and after the oxidation tests were analyzed by optical microscopy, SEM, and by EPMA. The layer thickness of SRZ was measured and compared to that of the specimen with aluminide coating, that means without additional coating.

Table II. The variation of sputter deposited films

\begin{tabular}{|c|c|c|c|}
\hline \multicolumn{2}{|c|}{ Name } & Composition (at.\%) & Thickness \\
\hline $\mathrm{A}$ & $\mathrm{Ru} / 5 \mu \mathrm{m}$ & $\mathrm{Ru} 100 \%$ & $5 \mu \mathrm{m}$ \\
\hline $\mathrm{B}$ & $\mathrm{Ru} / 1 \mu \mathrm{m}$ & $\mathrm{Ru} 100 \%$ & $1 \mu \mathrm{m}$ \\
\hline $\mathrm{C}$ & $\mathrm{Co} 50-\mathrm{Ru} 50 / 5 \mu \mathrm{m}$ & $\mathrm{Co} 50 \%-\mathrm{Ru} 50 \%$ & $5 \mu \mathrm{m}$ \\
\hline $\mathrm{D}$ & $\mathrm{Co} 80-\mathrm{Ru} 20 / 5 \mu \mathrm{m}$ & $\mathrm{Co} 80 \%-\mathrm{Ru} 20 \%$ & $5 \mu \mathrm{m}$ \\
\hline $\mathrm{E}$ & $\mathrm{Co} / 5 \mu \mathrm{m}$ & $\mathrm{Co} 100 \%$ & $5 \mu \mathrm{m}$ \\
\hline
\end{tabular}

\section{$\underline{\text { Results }}$}

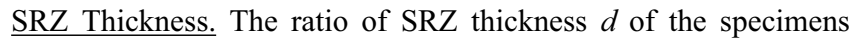
with additional coatings to the specimen with aluminide coating after the oxidation test is shown in Figure 5. SRZ thickness of the specimens $\mathrm{A}: \mathrm{Ru} / 5 \mu \mathrm{m}, \mathrm{C}: \mathrm{Co} 50-\mathrm{Ru} 50 / 5 \mu \mathrm{m}$, and D:Co80-Ru20/5 $\mu \mathrm{m}$ were no more than half of that of the specimen with aluminide coating. Those of the specimens $\mathrm{B}: \mathrm{Ru} / 1 \mu \mathrm{m}$ and $\mathrm{E}: \mathrm{Co} / 5 \mu \mathrm{m}$ were only slightly thinner than that of the specimen with aluminide coating.

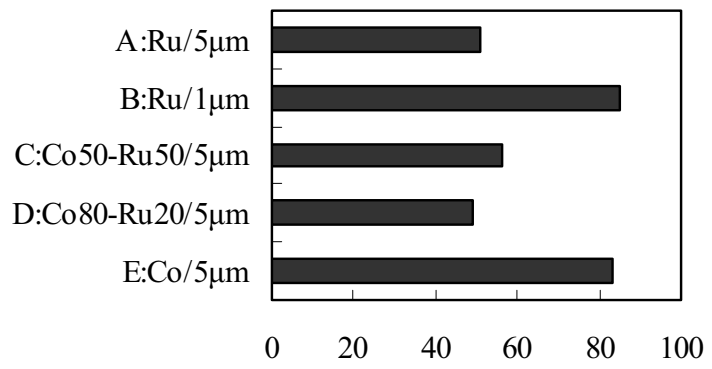

SRZ thickness ratio $d / d$ Aluminide-coating $(\%)$

Figure 5. SRZ thickness ratio of the specimens with additional coatings to the specimen with aluminide coating after the oxidation test in air at $1373 \mathrm{~K}$ in 500 hours. 
Oxidation Resistance. The weight changes of the specimens with additional coatings during the oxidation test in air at $1373 \mathrm{~K}$ in 500 hours is shown in Figure 6 . The specimens with aluminide coating and without coating are also plotted for reference. All the specimens with additional coatings showed good oxidation resistance equivalent to that of the specimen with aluminide coating. The specimen without coating showed large weight decrease due to scale separation. It was confirmed that the oxidation resistance is improved by the application of these coatings.

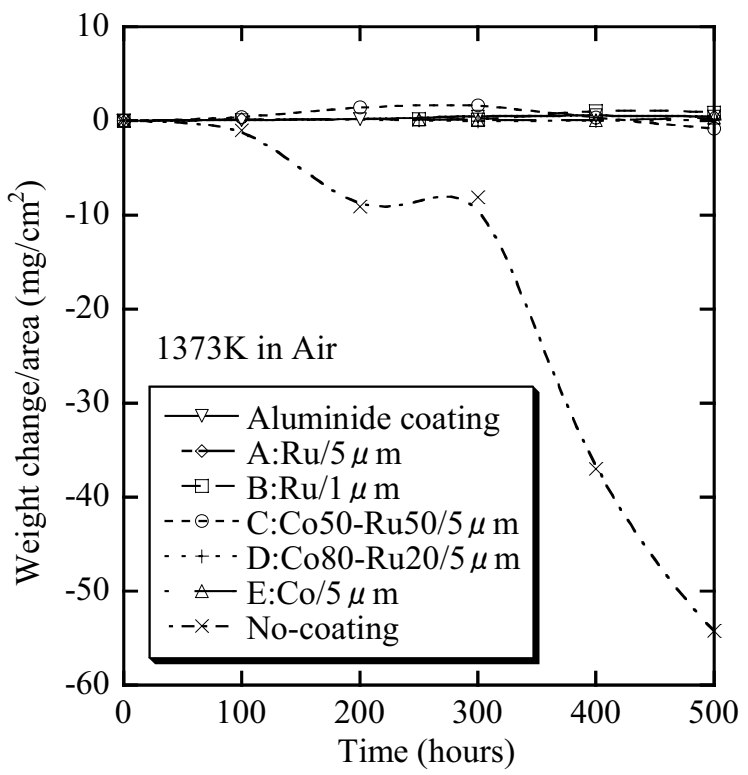

Figure 6. Weight changes of the specimens at $1373 \mathrm{~K}$ in air.

Microstructures. In the case of pure $\mathrm{Ru}$ deposition: The cross-sectional microstructure of the specimen $\mathrm{A}: \mathrm{Ru} / 5 \mu \mathrm{m}$ before the oxidation test is shown in Figure 7-(a). Ru concentrated in the upper part of the additive zone and also in the bottom part slightly. $\mathrm{Ni}$ was distributed in the middle part and $\mathrm{Al}$ was distributed in the entire additive zone. The diffusion zone was much thinner than that of the specimen with aluminide coating. It consisted of granular or needle-like precipitates.

The microstructure after the oxidation test is shown in Figure 7-(b). The diffusion zone had transformed into a line of granular precipitates and SRZ were formed below. Fine granular precipitates as small as about $0.5-1 \mu \mathrm{m}$ in diameter distributed in the most part of SRZ. A few needle-like precipitates were also formed in SRZ, however most of them were thin and as short as about $3-5 \mu \mathrm{m}$. A secondary phase was formed in the additive zone. $\mathrm{Ru}$ and $\mathrm{Al}$ concentrated in this phase. The content of $\mathrm{Al}$ under the coating layer had scarcely increased, whose X-ray intensity was no more than 1.05-1.1 times as high as in the substrate. Ru was distributed from the coating layer to the upper part of SRZ. Its $\mathrm{X}$-ray intensity just under the coating layer was about 2.5 times as high as that in the substrate.

The microstructure of the specimen $\mathrm{B}: \mathrm{Ru} / 1 \mu \mathrm{m}$ before the oxidation test was almost the same to that of the specimen with aluminide coating, except that $\mathrm{Ru}$ concentrated in the upper part of the additive zone. After the oxidation test, needle-like precipitates as long as about $10-15 \mu \mathrm{m}$ were formed obliquely in SRZ. A secondary phase composed of $\mathrm{Ru}$ and $\mathrm{Al}$ was formed in the additive zone like in specimen A. Al was distributed from the coating layer to SRZ decreasing gently, whose X-ray intensity under the coating layer had increased to 1.5 times as high as that in the substrate.

In the case of $\mathrm{Co}-\mathrm{Ru}$ deposition: The microstructure of the specimen C:Co50-Ru50/5 $\mu \mathrm{m}$ before the oxidation test is shown in Figure 8-(a). Co concentrated in the upper part of the additive zone and in the diffusion zone. Ru concentrated in the lower part of the additive zone. Thin diffusion zone consisted of needle-like precipitates perpendicular to the interface.

The microstructure after the oxidation test is shown in Figure 8-(b). Fine granular precipitates were distributed in most of the SRZ. The diameters of these granular precipitates were about $1-2 \mu \mathrm{m}$ in the upper part and as small as about $0.5 \mu \mathrm{m}$ in the lower part of SRZ. Needle-like precipitates perpendicular to the interface were formed under SRZ in the substrate. A secondary phase composed of $\mathrm{Ru}$ and $\mathrm{Al}$ was formed in the additive zone like in specimen A. $\mathrm{Ru}$ was distributed from the coating layer to the upper part of SRZ. Its X-ray intensity just under the coating layer was about 2.2 times as high as in the substrate.

The structure of the specimen D:Co80-Ru20/5 $\mu \mathrm{m}$ before the oxidation test was similar to the specimen C. Needle-like precipitates as large as about $10-20 \mu \mathrm{m}$ were observed in SRZ after the oxidation test, however its amount was very small. The gamma matrix remained to a large extent except in the very neighborhood of these needle-like precipitates.

In the case of pure Co deposition (the specimen E:Co/5 $\mu \mathrm{m}$ ): $\mathrm{Co}$ and $\mathrm{Al}$ were distributed in the entire additive zone. The diffusion zone was relatively thick and consisted of granular or needle-like precipitates. After the oxidation test, granular precipitates which were about $1-3 \mu \mathrm{m}$ in diameter were distributed in the upper part of SRZ. Needle-like precipitates were distributed below, which became longer in the lower part. Both $\mathrm{Co}$ and $\mathrm{Al}$ had diffused inward so that they were distributed from the coating layer to the substrate almost uniformly.

\section{Discussion}

Effect of pure $\mathrm{Ru}$ deposition. $\mathrm{Ru}$ deposition prior to aluminide coating proved to be effective on the reduction of SRZ as shown in Figure 5. The mechanism of SRZ reduction is thought to be as follows: First, the presence of a sufficient amount of $\mathrm{Ru}$ in the coating layer reduces the driving force for its outward diffusion from the substrate. It prevents the depletion of $\mathrm{Ru}$ content under the coating layer, maintaining the phase stability. Thus SRZ formation is restricted. Second, the formation of a secondary phase of $\mathrm{Ru}-\mathrm{Al}$ compound in the coating layer keeps $\mathrm{Al}$ from diffusing into the substrate. It restricts the increase of $\mathrm{Al}$ content under the coating layer, so that SRZ formation is restricted. It is reported that RuAl has a considerably higher melting point than NiAl so that RuAl will be stable for a substantial time [9].

In the case of the specimen $\mathrm{B}: \mathrm{Ru} / 1 \mu \mathrm{m}$, most of deposited $\mathrm{Ru}$ had diffused to the coating surface after aluminide coating treatment. So the amount of $\mathrm{Ru}$ at the coating/substrate interface was insufficient to prevent the diffusion of $\mathrm{Al}$ and $\mathrm{Ru}$. It may be the reason of the failure in SRZ reduction. Therefore it can be said that a certain amount of Ru is necessary to reduce SRZ. 

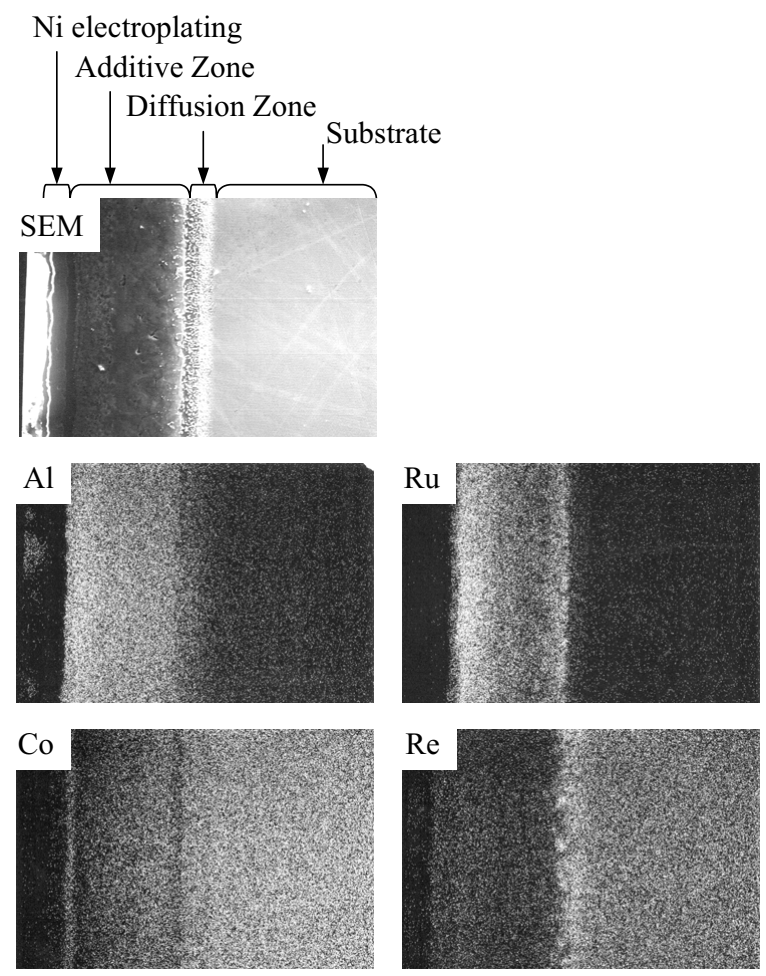

$\overline{20 \mu \mathrm{m}}$

(a) Before the oxidation test
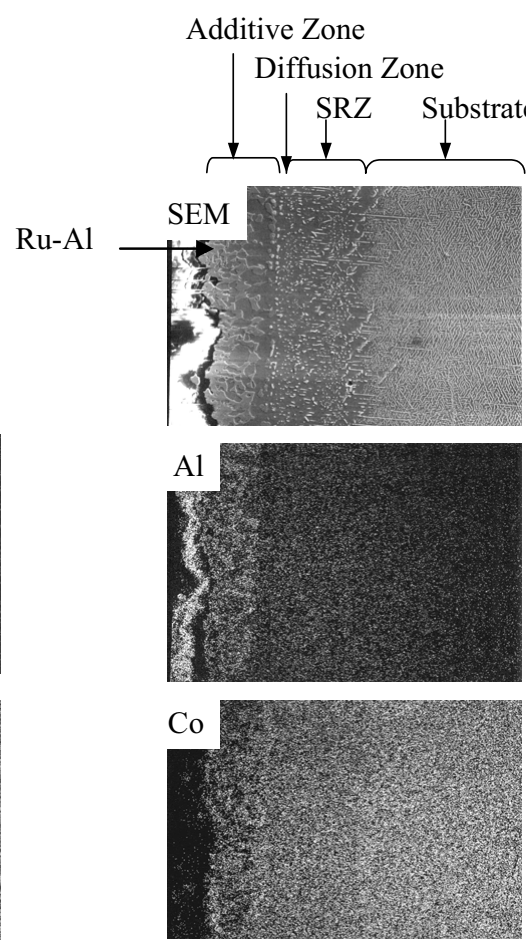

(b) After the oxidation test at $1373 \mathrm{~K}$ in 500 hours air
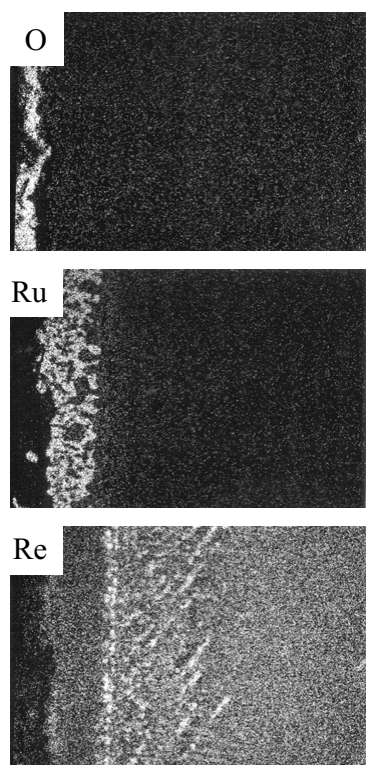

$2 \overline{0 \mu} \mathrm{m}$

Figure 7. Cross-sectional microstructure and characteristic X-ray images of the specimen A:Ru/5 $\mu \mathrm{m}$.

Ni electroplating
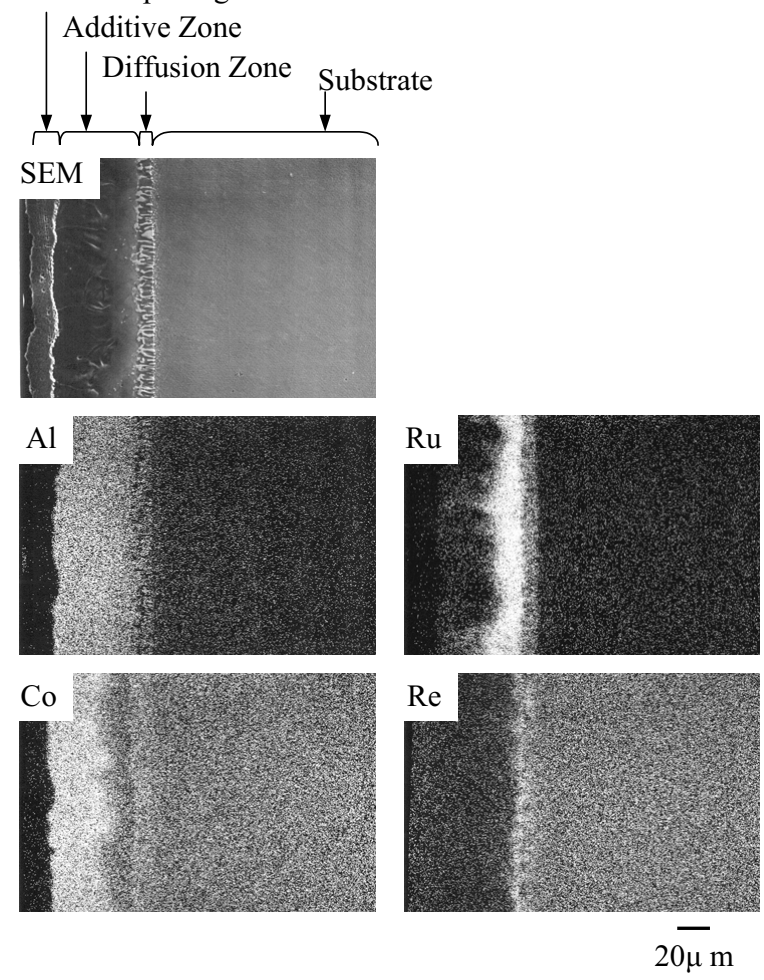

(a) Before the oxidation test
Additive Zone
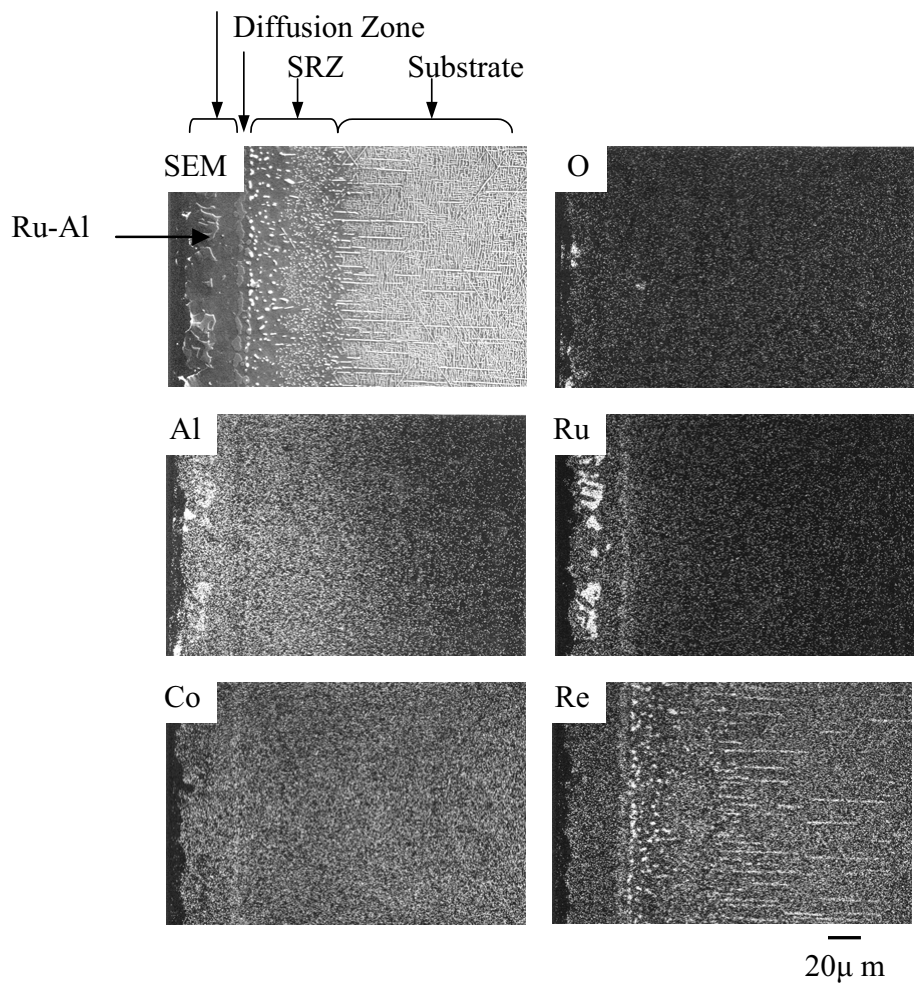

(b) After the oxidation test at $1373 \mathrm{~K}$ in 500 hours air

Figure 8. Cross-sectional microstructure and characteristic X-ray images of the specimen C:Co50-Ru50/5 $\mu \mathrm{m}$. 
Effect of Co-Ru deposition. Co-Ru deposition is also effective for $\mathrm{SRZ}$ reduction. Moreover the effect is equivalent to pure $\mathrm{Ru}$ deposition in $5 \mu \mathrm{m}$ thickness in spite of the fact that the total amount of deposited $\mathrm{Ru}$ is smaller. Therefore it is said that Co-Ru deposition can reduce SRZ with a smaller amount of Ru than pure $\mathrm{Ru}$ deposition. When $\mathrm{Ru}$ is deposited with $\mathrm{Co}, \mathrm{Ru}$ concentrates in the lower part of the additive zone and Co concentrates in the upper part after aluminide coating treatment. It is supposed that Co diffuses outward preferentially compared to $\mathrm{Ru}$ and combines with $\mathrm{Al}$ to form the additive zone of $\mathrm{Co}-\mathrm{Al}$ compound during aluminide coating treatment. The $\mathrm{Al}$ that diffused further inward combines with $\mathrm{Ru}$ to form the lower part of the additive zone of $\mathrm{Ru}-\mathrm{Al}$ compound, as the internal layer. It is thought that the existence of this internal layer with a high concentration of $\mathrm{Ru}$ at the coating/substrate interface contributes to a more effective SRZ reduction than pure $\mathrm{Ru}$ deposition.

\section{Conclusions}

The followings conclusions can be drawn from the results obtained in this investigation:

1 The growth of SRZ is predominantly controlled by the inward diffusion of $\mathrm{Al}$ from the coating layer and the presence of refractory elements in the substrate, such as Re. This study further revealed that the outward diffusion of $\mathrm{Ru}$ from the substrate to the coating layer destabilized the microstructure and lead to SRZ formation.

2 A certain amount of $\mathrm{Ru}$ deposition prior to aluminide coating can reduce SRZ.

3 Co-Ru deposition prior to aluminide coating can reduce SRZ with a smaller amount of $\mathrm{Ru}$ than pure $\mathrm{Ru}$ deposition.

\section{Acknowledgement}

The authors would like to express their thanks to the New Energy and Industrial Technology Development Organization (NEDO) and the Ministry of Economy, Trade and Industry (METI), who gave them the opportunity to conduct the "Research and Development of Environmentally Compatible Propulsion System for Next-Generation Supersonic Transport" (ESPR) project.

\section{References}

1. W.S. Walston, J.C. Schaeffer and W.H. Murphy, "A New Type of Microstructural Instability in Superalloys - SRZ", Superalloys 1996, ed. R.D.. Kissinger, et al, (Warrendale, PA: TMS, 1996), 9-18.

2. J. C. Zhao et al., "Materials for Protection of Substrates at High Temperature, Articles Made therefrom, and Method for Protecting Substrates", U. S. Patent 6,148,141, (2003).

3. W. S. Walston et al., "Nickel Base Superalloy and Article", U. S. Patent 5,482,789, (1996).

4. H. Harada et al., Proc. of $2^{\text {nd }}$ International Symposium on High Temperature Materials 2001, Tsukuba, Japan, (2001), 30-31.

5. J. Burke et al., The kinetics of phase transformations in metals translated from English by K. Hirano and H. Hori (Kyoritsu, Tokyo, 1972), 190.

6. P. Shewmon et al., Diffusion in Solids, 2nd ed., TMS, Warrendale, PA (1989), 71.

7. L. N. Lariko et al., Diffusion Process in Ordered Alloys (New Delhi, India: Armerind Publishing Co., 1981), 117.
8. R. A. Swalin and A. Martin, Trans. AIME, 206 (1956), 567.

9. I. T. Spitsberg et al., "Diffusion Barrier Layer", U. S. Patent $6,306,524,(2001)$ 